\title{
Effects of fasting on the composition of gallbladder bile
}

\author{
H M BLOCH,* J R THORNTON, K W HEATON $\dagger$ \\ With the technical assistance of J S Nicholls \\ From the University Department of Medicine, Bristol Royal Infirmary, Bristol
}

SUMMARY Gallbladder bile was aspirated from the duodenum in nine healthy women after three separate periods of fasting after a standardised meal. Mean cholesterol saturation index was significantly greater after a 15 hour fast $(1 \cdot 35 \pm 0 \cdot 08)$ than after a 10 hour fast $(1.05 \pm 0 \cdot 10)$. However, after 20 hours of fasting, mean cholesterol saturation index had fallen to $1 \cdot 13 \pm 0 \cdot 10$. Total biliary lipid concentration was unaffected. These findings suggest that fasting has a series of effects on gallbladder bile and that bile sampling should be carried out at a standardised period of time after the last meal.

In patients with cholesterol gallstones both hepatic and gallbladder bile contain an excessive amount of cholesterol in relation to the solubilising bile acids and phospholipids. ${ }^{12}$ Several studies have shown that hepatic bile contains a greater proportion of cholesterol after an overnight fast than in the fed state. $^{3-5}$ The effect of fasting on gallbladder bile was investigated by Williams et al. ${ }^{6}$ who studied normal men and women fasted for 9, 12 and 16 hours. The molar percentage of cholesterol rose with increasing duration of the fast but the difference was significant only in women. These ${ }^{6}$ and earlier workers ${ }^{4}$ suggested that fasting may contribute to cholesterol gallstone formation. However, an additional study demonstrated that a prolonged fast of four to six days reduced the proportion of cholesterol in gallbladder bile. ${ }^{7}$ Taken together, these studies suggest that, as a fast continues, the cholesterol saturation of bile may rise initially and then decline. To determine if these changes occur, we have studied the effects of different periods of fasting on the composition of human gallbladder bile.

\section{Methods}

\section{PATIENTS}

Nine healthy premenopausal women aged 27 to 46 years (mean 40 years) gave informed consent to be

\footnotetext{
-Present address: Department of Medicine, University of the Witwatersrand, Hillbrow 2001, Pretoria, South Africa.

+Address for reprint requests: Dr K W Heaton, University Department of Medicine, Bristol Royal Infirmary, Bristol BS2 8HW.

Received for publication 5 August 1980
}

studied; none was taking any medication, including oral contraceptives, and all had normal standard liver function tests. Oral cholecystograms were not performed on ethical grounds but no subject had symptoms suggestive of gallbladder disease. The subjects maintained their usual diet throughout the period of study. Bile was collected from each of them on three separate occasions four weeks apart. To avoid possible fluctuations in bile composition related to the menstrual cycle ${ }^{8}$ bile samples were collected within the first five days of each subject's cycle.

After a standard solid food meal (supplied by us and containing $30 \mathrm{~g}$ protein, $45 \mathrm{~g}$ fat, and $96 \mathrm{~g}$ carbohydrate providing $3.72 \mathrm{MJ}$ ), the subjects were asked to fast for 10,15 , or 20 hours. The order of fasting periods was randomly allocated. Morning samples of bile-rich duodenal fluid were collected on to ice after duodenal intubation and intravenous injection of 50-75 units cholecystokinin (Boots Co., Ltd.). This method of bile sampling has been shown to reflect accurately the composition of gallbladder bile. ${ }^{9}$ Five millilitres of bile were saved and divided into aliquots before storage at $-20^{\circ} \mathrm{C}$; the remainder was reinstilled.

All samples from each subject were analysed in the same batch. Total bile salt concentration ${ }^{10}$ and phospholipid concentration ${ }^{11}$ were measured using isopropanolic extracts. Cholesterol concentration was measured in whole bile using a modification of the Boehringer-Mannheim catalase method. ${ }^{12}$ The biliary cholesterol saturation index was calculated by the method of Thomas and Hofmann ${ }^{13}$ using the criteria of Hegardt and Dam. ${ }^{14}$ The ratio of the 
glycine conjugates of cholic, chenodeoxycholic, and deoxycholic acids was determined by thin-layer chromatography and enzymatic assay. ${ }^{15}$ The statistical significance of differences was calculated by Student's $t$ test.

\section{Results}

All subjects maintained a constant weight throughout the study period. The duration of the fast was usually within one hour of the intended period. In every case, cholecystokinin evoked a free flow of concentrated bile suggesting that gallbladder function was normal.

In eight of the nine subjects studied, bile was more saturated with cholesterol after the 15 hour fast than after the 10 hour fast (Figure), the respective saturation indices being $1 \cdot 34 \pm 0.08$ and $1.05 \pm 0.10 \quad(P<0.005)$. In three of the subjects, bile was unsaturated after the shorter fast but was supersaturated after the longer one. However, after 20 hours of fasting, the mean saturation index $(1 \cdot 13 \pm 0 \cdot 10)$ was significantly less $(\mathrm{P}<0.02)$ than after the 15 hour fast and did not differ significantly from the 10 hour value.

The mean molar percentages of cholesterol,

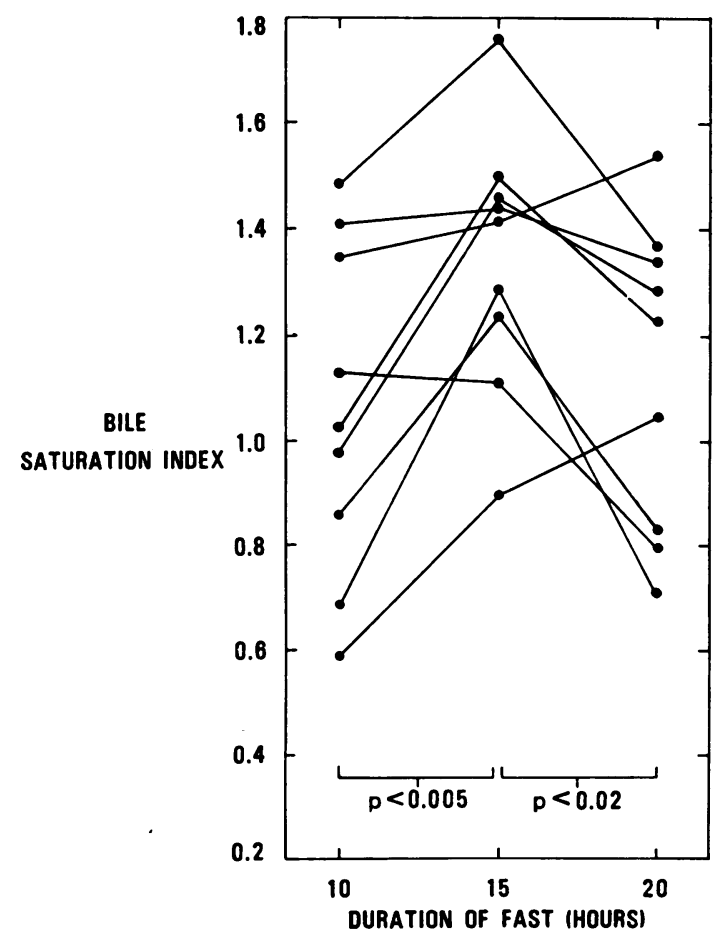

Figure Cholesterol saturation of gallbladder bile in nine subjects after three periods of fasting.
Table 1 Lipid composition of gallbladder bile after three different periods of fasting (mean $\pm S E M$ )

\begin{tabular}{|c|c|c|c|c|}
\hline $\begin{array}{l}\text { Duration of } \\
\text { fast (hr) }\end{array}$ & $\begin{array}{l}\text { Bile salts } \\
(\mathrm{mol} \%)\end{array}$ & $\begin{array}{l}\text { Phospholipid } \\
(\mathrm{mol} \%)\end{array}$ & $\begin{array}{l}\text { Cholesterol } \\
(\mathrm{mol} \%)\end{array}$ & $\begin{array}{l}\text { Total lipids } \\
\text { ( } \mathrm{mmol} / \mathrm{ml})\end{array}$ \\
\hline $\begin{array}{l}10 \\
15 \\
20\end{array}$ & $\begin{array}{l}71 \cdot 5 \pm 0 \cdot 9 \\
71 \cdot 5 \pm 1 \cdot 4^{*} \\
74 \cdot 0 \pm 1 \cdot 8^{*}\end{array}$ & $\begin{array}{l}21 \cdot 5 \pm 0 \cdot 6^{*} \\
20 \cdot 1 \pm 1 \cdot 0^{*} \\
19 \cdot 1 \pm 1 \cdot 2\end{array}$ & $\begin{array}{l}7 \cdot 0 \pm 0.7 \dagger \\
8 \cdot 6 \pm 0.6 \dagger \\
7 \cdot 0 \pm 0.8 \dagger\end{array}$ & $\begin{array}{l}33 \cdot 4 \pm 6 \cdot 6 \\
36 \cdot 8 \pm 15 \cdot 1 \\
33 \cdot 8 \pm 6 \cdot 4\end{array}$ \\
\hline
\end{tabular}

Table 2 Molar percentages of glycine-conjugates of the three major bile acids in gallbladder bile after three different periods of fasting (mean $\pm S E M$ )

\begin{tabular}{llll}
\hline $\begin{array}{l}\text { Duration of } \\
\text { fast (hr) }\end{array}$ & $\begin{array}{l}\text { Cholic } \\
\text { acid }\end{array}$ & $\begin{array}{l}\text { Chenodeoxycholic } \\
\text { acid }\end{array}$ & $\begin{array}{l}\text { Deoxycholic } \\
\text { acid }\end{array}$ \\
\hline 10 & $38 \cdot 1 \pm 3 \cdot 3$ & $29 \cdot 7 \pm 2 \cdot 4$ & $32 \cdot 2 \pm 4 \cdot 9$ \\
15 & $39 \cdot 8 \pm 3 \cdot 0$ & $29 \cdot 9 \pm 2 \cdot 8$ & $30 \cdot 3 \pm 3 \cdot 8$ \\
20 & $40 \cdot 3 \pm 3 \cdot 2$ & $28 \cdot 3 \pm 2 \cdot 9$ & $31 \cdot 4 \pm 4 \cdot 2$ \\
\hline
\end{tabular}

phospholipid, and bile acids, as well as the mean total biliary lipid concentrations, are shown in Table 1. The total lipid concentration was similar at all three sampling times. There was also no significant variation in the proportion of the major glycine-conjugated bile acids (Table 2).

\section{Discussion}

Thi s study confirms that fasting produces a rise in the cholesterol saturation of gallbladder bile but shows that this is a transitory phenomenon. While saturation index increases in the period between 10 and 15 hours of fasting, it declines if the fast is further prolonged. It appears that the maximum biliary saturation index produced by fasting occurs between 10 and 20 hours. Our findings are in agreement with and help to reconcile the apparent discrepancy between previous studies. These suggested that there is a rise in the cholesterol saturation of hepatic and gallbladder bile with an overnight fast ${ }^{3-6}$ but a fall in the cholesterol saturation index of gallbladder bile with a four to six day fast. ${ }^{7}$

This study does not reveal the mechanism of the initial rise in bile cholesterol saturation. However, during fasting, bile acids are to some extent sequestered in the relaxed gallbladder which temporarily interrupts their enterohepatic circulation. This causes a fall in bile acid secretion rate and hence the production of hepatic bile with a higher cholesterol content. ${ }^{316}$ This more saturated bile replenishes the gallbladder as its contents shrink through extraction of fluid. Our data suggest that such replenishment is still occurring after 10 hours of fasting.

A different mechanism must be invoked to explain the fall in bile cholesterol saturation with continued 
fasting. One possibility is reduced hepatic cholesterol synthesis leading to less saturated hepatic bile. In the rat liver the activity of the rate-limiting enzyme of cholesterol synthesis (hydroxymethyl-glutaryl coenzyme-A reductase) begins to decline within six to eight hours of fasting and reaches a minimum 14 hours after the last meal. ${ }^{17-19}$ Conceivably, the absence of dietary cholesterol also plays a part in this change.

Like previous workers, ${ }^{7}$ we did not find that fasting produced any changes in the individual bile acid composition of gallbladder bile.

The total biliary lipid concentration might have been expected to rise as the fast was prolonged. Its failure to do so could involve two factors. Firstly, the gallbladder might stop its concentrating activity within 10 hours of fasting. Secondly, there might be some emptying of the gallbladder during a fast, with replacement of gallbladder bile by the less concentrated hepatic bile. Recent work has shown that in healthy subjects (admittedly young men with a perfusion tube in the duodenum) there are indeed episodes of gallbladder emptying during the night. ${ }^{20}$

In conclusion, our findings suggest that fasting for between 10 and 20 hours may indeed increase the risk of gallstone formation, but this effect is counteracted by a more prolonged fast. The data also indicate that, in studies of human gallbladder bile, it is desirable to standardise the period of fasting before sampling the bile.

We are grateful to Miss C Henry for dietary assistance. HMB was in receipt of a British Council Bursary.

\section{References}

${ }^{1}$ Admirand WH, Small DM. The physicochemical basis of cholesterol gallstone formation in man. $J$ Clin Invest 1968; 47: 1043-52.

${ }^{2}$ Carey MC, Small DM. The physical chemistry of cholesterol solubility in bile. Relationship to gallstone formation and dissolution in man. $J$ Clin Invest 1978; 61: 998-1026.

${ }^{3}$ Shaffer EA, Braasch JW, Small DM. Bile composition at and after surgery in normal persons and patients with gallstones. Influence of cholecystectomy. $N$ Engl J Med 1972; 287: 1317-22.

"Metzger AL, Adler R, Heymsfield S, Grundy SM. Diurnal variation in biliary lipid composition. Possible role in cholesterol gallstone formation. $N$ Engl $J$ Med $1973 ; 288$ : 333-6.
${ }^{5}$ Northfield TC, Hofmann AF. Biliary lipid secretion in gallstone patients. Lancet 1973 ; 1 : 747-8.

${ }^{6}$ Williams NC, Morse JWI, MacDonald IA, Kotoor R, Riding MD. Increased lithogenicity of bile on fasting in normal subjects. Am J Dig Dis, 1977; 22: 189-94.

'Duane WC, Ginsberg RL, Bennion LJ. Effects of fasting on bile acid metabolism and biliary lipid composition in man. J Lipid Res 1976; 17: 211-9.

${ }^{8}$ Low-Beer TS, Wicks ACB, Heaton KW, Durrington P, Yeates J. Fluctuations of serum and bile lipid concentrations during the menstrual cycle. $B r M e d J 1977$; 1 : 1568-70.

${ }^{9}$ Vlahcevic ZR, Bell CC, Juttijudata P, Swell L. Bilerich duodenal fluid as an indicator of biliary lipid composition and its applicability to detection of lithogenic bile. Am J Dig Dis 1971 ; 16: 797-802.

${ }^{10}$ Iwata T, Yamasaki K. Enzymatic determination and thin-layer chromatography of bile acids in blood. J Biochem 1964; 56: 424-31.

${ }^{11} \mathrm{King}$ EJ. The colorimetric determination of phosphorus. Biochem J 1932; 26: 292-7.

${ }^{12}$ Bolton $\mathrm{CH}$, Nicholls JS, Heaton KW. Estimation of cholesterol in bile: assessment of an enzymatic method. Clin Chim Acta 1980; 105: 225-30.

${ }^{13}$ Thomas PJ, Hofmann AF. A simple calculation of the lithogenic index of bile; expressing biliary lipid composition on rectangular coordinates. Gastroenterology $1973 ; 65$ : 698-700.

${ }^{14}$ Hegardt FG, Dam H. The solubility of cholesterol in aqueous solutions of bile salts and lecithin. $Z$ Ernährung 1971 ; 10: 223-33.

${ }^{15}$ Wicks ACB, Yeates J, Heaton KW. Bran and bile: time-course of changes in normal young men given a standard dose. Scand J Gasterenterol 1978; 13: 289-92.

${ }^{16}$ Dowling RH, Mack E, Small DM. Biliary lipid secretion and bile composition after acute and chronic interruption of the enterohepatic circulation in the Rhesus monkey. IV. Primate biliary physiology. J Clin Invest 1971; 50: 1917-26.

${ }^{17}$ Edwards PA, Muroya H, Gould RG. In vivo demonstration of the circadian rhythm of cholesterol biosynthesis in the liver and intestine of the rat. J Lipid Res $1972 ; 13: 396-401$.

${ }^{18}$ Gregory $\mathrm{KW}$, Smith CZ, Booth R. Diurnal variations in rat liver 3-hydroxy-3-methylglutaryl-coenzyme $A$ reductase activity in relation to feeding. Biochem $J, 1972$; 130: 1163-5.

${ }^{19}$ Dugan RE, Slakey LL, Briedis AV, Porter JW. Factors affecting the diurnal variation in the level of $\beta$-hydroxy$\beta$ methylglutaryl coenzyme A reductase and cholesterolsynthesizing activity in the rat liver. Arch Biochem Biophys 1972; 152: 21-7.

${ }^{20}$ Van Berge Henegouwen GP, Hofmann AF. Nocturnal gallbladder storage and emptying in gallstone patients and healthy subjects. Gastroenterology 1978; 75: 879-85. 